\title{
Análise radiográfica computadorizada da reabsorção radicular apical após a utilização de duas mecânicas ortodônticas
}

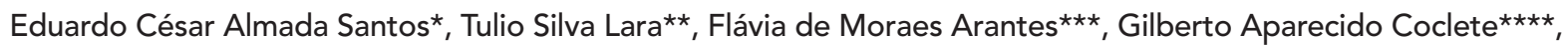

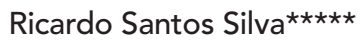

\begin{abstract}
Resumo
Objetivo: a reabsorção radicular apical é uma condição comumente observada durante e após o tratamento ortodôntico e fatores como tipo de aparelhagem ortodôntica utilizada, magnitude das forças aplicadas e duração do tratamento podem estar relacionados ao processo de arredondamento do ápice radicular. Buscou-se avaliar, por meio de imagens radiográficas computadorizadas, a quantidade de reabsorção no ápice radicular, quando da utilização de duas diferentes técnicas de mecânica ortodôntica fixa: Edgewise com acessórios padrão e Edgewise com acessórios totalmente programados. Metodologia: a amostra constituiu-se de 20 pacientes tratados pelo mesmo profissional na Clínica de Ortodontia da Faculdade de Odontologia de Araçatuba - UNESP. Os pacientes foram divididos em dois grupos: grupo 1 (Tratados com Edgewise com acessórios padrão e fios de aço) e grupo 2 (Tratados com Edgewise com acessórios totalmente programados e fios de níquel-titânio). A avaliação radiográfica digital foi realizada por um único operador por meio de exposições radiográficas digitais feitas no início do tratamento ortodôntico, após retração de caninos e final de tratamento, utilizando o sistema de escores proposto por Levander e Malmgren (1988). Resultados e Conclusões: a análise dos escores permitiu concluir que o tratamento ortodôntico empregando a técnica Edgewise com acessórios totalmente programados e fios de níquel-titânio apresentou menores graus de reabsorção radicular apical, em comparação à técnica Edgewise com acessórios padrão e fios de aço. Observou-se que, independentemente da técnica empregada, o tratamento ortodôntico como um todo apresentou um grau moderado de reabsorção radicular apical.
\end{abstract}

Palavras-chave: Ortodontia corretiva. Reabsorção da raiz. Interpretação de imagem assistida por computador.

\footnotetext{
* Professor Assistente Doutor da Disciplina de Ortodontia do Departamento de Odontologia Infantil e Social da Faculdade de Odontologia de Araçatuba - UNESP.

** Aluno do curso de Mestrado do Programa de Pós-Graduação em Odontologia, área de Concentração Ortodontia, da Faculdade de Odontologia de Araçatuba - UNESP.

*** Estagiária da Disciplina de Ortodontia da Faculdade de Odontologia de Araçatuba - UNESP.

**** Professor Assistente Doutor da Disciplina de Radiologia do Departamento de Patologia e Propedêutica Clínica da Faculdade de Odontologia de Araçatuba - UNESP.

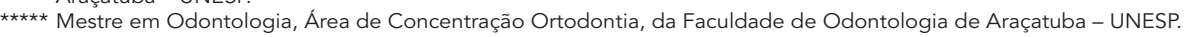




\section{INTRODUÇÃO}

A reabsorção radicular apical é uma condição comumente observada durante e após o tratamento ortodôntico, levando a um arredondamento do ápice radicular ${ }^{5,20,21,22,25}$. Esta situação resulta de uma complexa combinação das atividades biológicas, inerentes a cada paciente, associada às forças mecânicas empregadas ${ }^{19}$ e pode ocorrer em 39\% a $99 \%$ dos pacientes ortodônticos ${ }^{4,25}$.

Como características microscópicas, temos que o resultado da força mecânica aplicada nas estruturas do pericemento cria oportunidade para que unidades osteorremodeladoras (BMUs) iniciem a reabsorção em dentina exposta, resultando na reabsorção radicular inflamatória ${ }^{1,8}$. Esta, geralmente suave, mostra-se assintomática e preserva a vitalidade pulpar ${ }^{29}$, estabelecendo uma condição insignificante do ponto de vista clínico, com prognóstico geralmente favorável ${ }^{24}$.

Apesar de reconhecidamente ser um processo de natureza multifatorial ${ }^{7,26}$, o conhecimento dos fatores que podem levar a esse tipo de reabsorção associada ao tratamento ortodôntico é bastante importante para que o profissional possa tomar atitudes clínicas coerentes, no que se refere a um diagnóstico correto, mecanoterapia que respeite as estruturas biológicas e acompanhamento radiográfico periódico.

Alguns fatores que podem estar relacionados à reabsorção radicular têm sido estudados e descritos na literatura e incluem predisposição individual, idade ${ }^{18}$ e gênero do paciente ${ }^{12}$, anatomia da raiz ${ }^{8,16}$, movimentação de dentes tratados endodonticamente $^{22,29}$, hábitos adversos como onicofagia, estágio de desenvolvimento radicular $\mathrm{r}^{23,28}$, o tipo de aparelhagem ortodôntica utilizada ${ }^{13,20}, \mathrm{o}$ tipo de movimentação dentária ${ }^{9}$, magnitude das forças aplicadas e a duração do tratamento ${ }^{5,12}$.

Ainda se questiona se o emprego da técnica Edgewise convencional com braquetes padrão e fios de aço inoxidável ou Edgewise com acessórios totalmente programados e arcos de níquel-titânio, por serem mecanoterapias distintas, poderia levar a diferentes respostas biológicas quanto à reabsorção radicular apical.

Diante desta dúvida, objetivou-se analisar, por meio de imagens radiográficas computadorizadas, a quantidade de reabsorção no ápice radicular quando da utilização de duas diferentes técnicas de mecânica ortodôntica fixa: Edgewise com acessórios padrão e fios de aço inoxidável e Edgewise com acessórios totalmente programados e fios de níquel-titânio.

\section{MATERIAL E MÉTODOS}

A amostra constituiu-se de 20 pacientes que procuraram a Faculdade de Odontologia de Araçatuba - UNESP, buscando tratamento ortodôntico. $\mathrm{Na}$ pesquisa, de caráter prospectivo, todos os pacientes apresentavam má oclusão de Classe I ou Classe II de Angle, com apinhamento anterior nos arcos superior e inferior, sem histórico prévio de tratamento endodôntico, trauma ou tratamento ortodôntico. Nenhum paciente apresentava reabsorção anterior ao tratamento e todos foram tratados com extração de primeiros pré-molares superiores e inferiores, sem necessidade de ancoragem, respeitando-se o seguinte protocolo:

- retração inicial de caninos;

- nivelamento superior e inferior;

- retração anterior superior e inferior.

A seqüência de fios utilizada, tanto para fios de aço quanto para fios de níquel-titânio, foi: 0,014"/ $0,016 " / 0,018 " / 0,020 " / 0,019$ " x 0,025". Utilizaram-se braquetes com encaixe 0,022 " x 0,028 " da marca Morelli ${ }^{\circledR}$. Ressalta-se que todos os pacientes foram tratados sempre pelo mesmo profissional na Disciplina de Ortodontia, num periodo médio de 2 anos, respeitando-se a seqüência da mecanoterapia e procurando aplicar os mesmos níveis de força em cada etapa.

Para a realização do estudo, os pacientes foram divididos igualmente em dois grupos (Tab. 1).

Os pacientes foram submetidos a exposições radiográficas periapicais na Clínica de Radiologia da Faculdade de Odontologia de Araçatuba - UNESP, 
no início do tratamento ortodôntico, após a fase de retração de caninos e no final do tratamento. As exposições abrangeram a área correspondente aos dentes incisivos superiores (Fig. 1). Foi realizado o método do paralelismo com suportes da Hanshin Tecnical Lab ${ }^{3}$. Utilizou-se, para todas as tomadas radiográficas, o mesmo aparelho de raios-x - Spectro II (Dabi-Atlante, Ribeirão Preto / SP, Brasil), de 70 Kvp e 10 mA.

Para se obter as imagens, utilizou-se o sistema de imagem digital, que proporciona melhores condições de padronização, análise e manipulação das imagens obtidas ${ }^{2}$, além de submeter o paciente à exposição uma menor dose de radiação ${ }^{17}$. O aparetho empregado, descrito como Digora for Windows 1.51 (Soredex, Orion Company, Finland), captura a informação radiográfica em uma placa óptica contendo fósforo ativado ${ }^{30}$, cuja leitura é efetuada por um dispositivo a laser conectado a um computador (Fig. 2). A placa óptica apresenta dimensões de 30x40mm, sendo necessário o tempo de exposi-

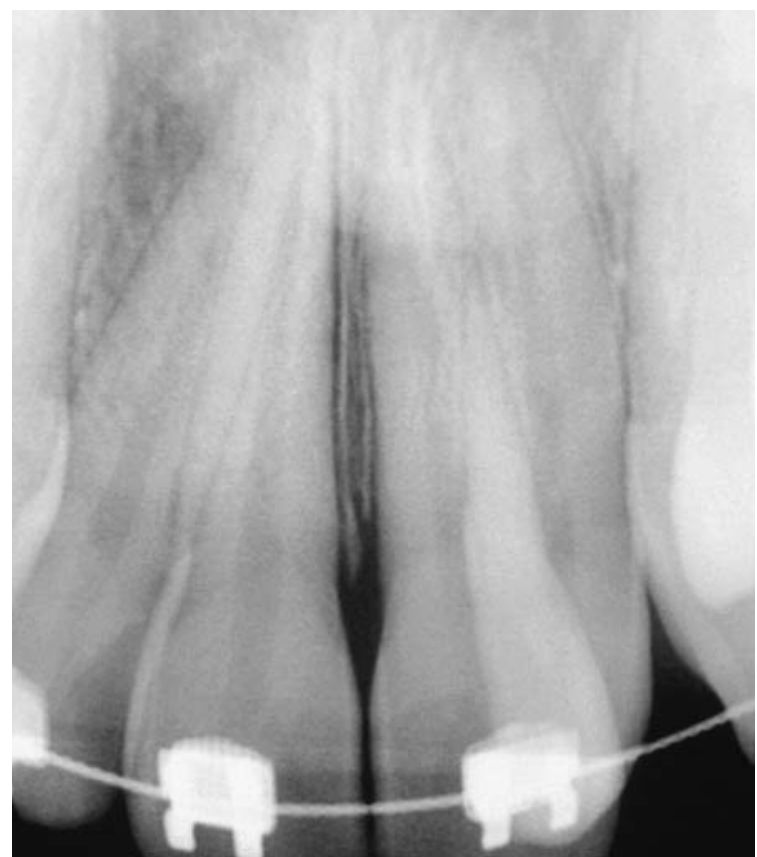

FIGURA 1 - Radiografia digitalizada, tomada no início do tratamento ortodôntico, imediatamente após a colocação do aparelho fixo em um paciente que compôs o grupo amostral. ção de 0,18 s para a obtenção de cada imagem.

Depois de realizado o exame radiográfico, as imagens foram armazenadas para a realização da análise do ápice radicular por meio da manipulação de imagens do software do programa de imagem do Digora ${ }^{10}$. Para a classificação do grau de reabsorção radicular apresentado, utilizou-se o sistema de escores proposto por Levander e Malmgren ${ }^{16}$, em 1988 (Fig. 3). Os incisivos centrais superiores foram eleitos para a determinação dos escores, já que a maior prevalência de reabsorção recai sobre estes dentes ${ }^{26}$.

A análise do ápice radicular foi realizada por

Tabela 1 - Distribuição dos pacientes de acordo com o tipo de mecanoterapia utilizada.

\begin{tabular}{cc}
\hline grupos & tipo de mecanoterapia \\
\hline grupo $1(n=10)$ & $\begin{array}{c}\text { Edgewise convencional com acessórios padrão, } \\
\text { utilizando-se apenas fios de aço inoxidável }\end{array}$ \\
grupo $2(n=10)$ & $\begin{array}{c}\text { Edgewise com acessórios totalmente programa- } \\
\text { dos, utilizando-se fios de níquel-titânio }\end{array}$ \\
\hline
\end{tabular}

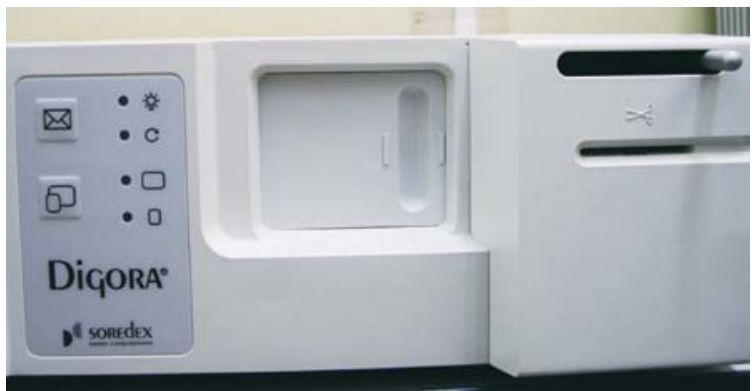

FIGURA 2 - Aparelho Digora, utilizado para a captura das imagens digitais.

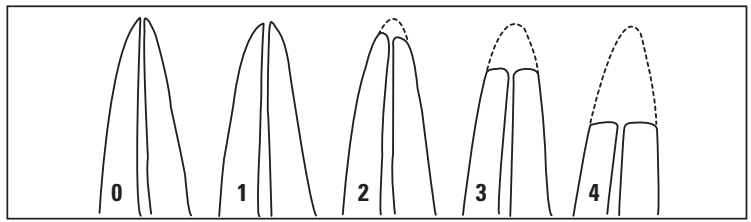

FIGURA 3 - Sistema de escores proposto por Levander e Malmgren ${ }^{16}$, em 1988 (0 - ausência de reabsorção; 1 - reabsorção suave, contorno apical irregular; 2 - reabsorção moderada, pequena perda radicular, com 0 ápice exibindo um contorno praticamente reto; $\mathbf{3}$ - reabsorção acentuada, perda de quase $1 / 3$ do comprimento radicular; 4 - reabsorção extrema, com perda de mais de $1 / 3$ do comprimento radicular). 
um único examinador em todas as radiografias. A avaliação foi repetida três vezes e considerou-se os escores coincidentes para a interpretação dos resultados.

\section{Análise estatística}

Foram registradas as variáveis descritivas média e desvio-padrão dos escores de reabsorção radicular, bem como suas freqüências. $O$ teste de Mann-Whitney foi realizado para testar a hipótese de não haver diferença entre os grupos 1 e 2 . A escolha pelo modelo monocaudal justifica-se pela única possibilidade ser a ocorrência de diminuição do tamanho radicular.

\section{RESULTADOS}

No gráfico 1 foram dispostos os escores relativos à reabsorção apical nos incisivos centrais superiores identificados após os tratamentos com as duas técnicas propostas.

$\mathrm{Na}$ tabela 2 foi disposto o sumário dos parâmetros estatísticos encontrados, resultantes da comparação da média dos escores dos dois grupos

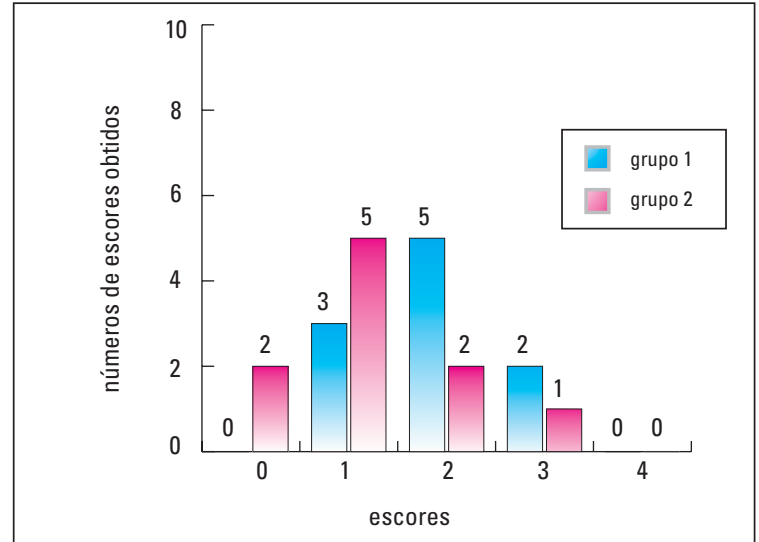

GRÁFICO 1 - Número de escores determinados por grupo (Grupo 1 - técnica com braquetes padrão e fios de aço inoxidável e grupo 2 - técnica com braquetes totalmente programados e fios de níquel-titânio).

Tabela 2 - Sumário dos valores da análise estatística.

\begin{tabular}{ccc}
\hline função estatística & grupo 1 & grupo 2 \\
\hline tamanho da amostra $(\mathrm{n})$ & 10 & 10 \\
média & 1,9 & 1,2 \\
desvio-padrão & 0,7397 & 0,98189 \\
limite de confiança mínimo $(95 \%)$ & 1,372 & 0,5427 \\
limite de confiança máximo $(95 \%)$ & 2,428 & 1,857 \\
\hline
\end{tabular}

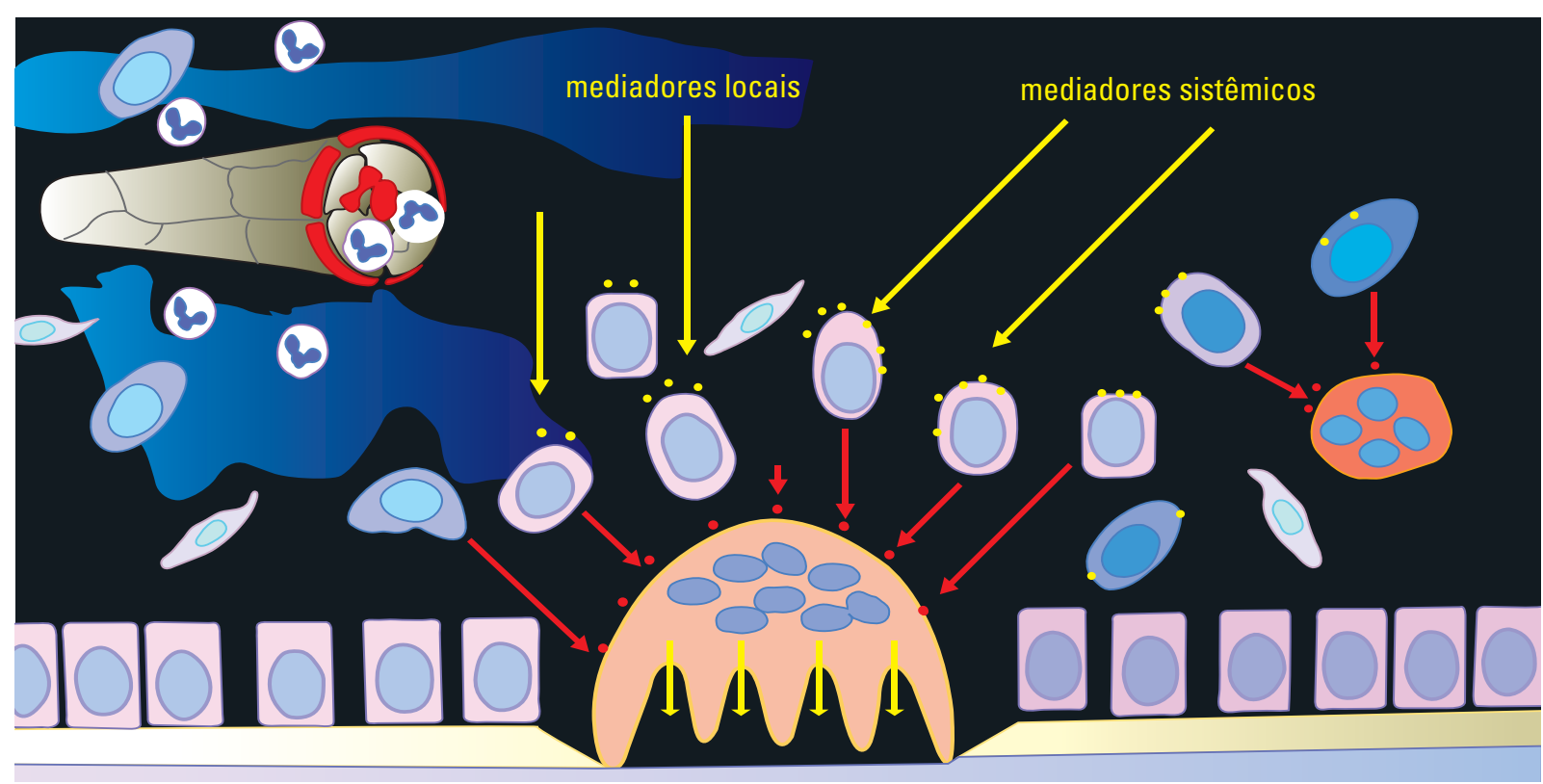

FIGURA 4 - Representação esquemática da instalação da unidade osteorremodeladora sobre a superfície óssea desnuda. Um micro-ambiente se estabelece a partir da firme adesão dos clastos. 0 início do processo reabsortivo levará à formação das lacunas de Howship - socavações superficiais e múltiplas nas superfícies ósseas (extraído de Consolaro $\left.{ }^{8}, 2002\right)$. 
avaliados.

O teste de Mann-Whitney identificou uma diferença estatisticamente significante no grau de reabsorção radicular entre os grupos 1 e 2 $(\mathrm{p}=0,0466)$. O grupo 2, tratado com braquetes totalmente programados e fios de níquel-titânio, apresentou menores graus de reabsorção radicular apical quando comparado ao grupo 1 , tratado com braquetes padrão e fios de aço inoxidável.

\section{DISCUSSÃO}

Microscopicamente, a reabsorção normal e patológica dos tecidos mineralizados se processa através da ação de um conjunto celular denominado unidade osteorremodeladora (BMU). Esta unidade é composta pelos clastos interagindo com mediadores liberados localmente pelos osteoblastos e células mononucleares da mesma linhagem dos macrófagos, distribuídos próximos à superfície onde se instala o processo de reabsorção ${ }^{8}$ (Fig. 4).

O emprego de radiografias periapicais tem sido o método de escolha para a avaliação de reabsorção radicular apical provocada pelo tratamento ortodôntico. Isto se deve à relação custo-benefício do método, em detrimento às radiografias em norma lateral ou mesmo às panorâmicas, que apresentam um resultado e uma confiabilidade inferiores ${ }^{5,16}$, como também em detrimento às tomografias computadorizadas que, apesar de apresentarem resultados fidedignos, consistem em um custo muito elevado, além de exporem o paciente a um maior nível de radiação ${ }^{27}$.

Neste estudo foi utilizada a técnica radiográfica do paralelismo com a imagem digital, a qual elimina o processamento radiográfico, já que a imagem aparece na tela do computador de forma simultânea, além de expor o paciente a uma dose ínfima de radiação.

Considerando a dificuldade de se obter tomadas radiográficas padronizadas, o método proposto por Levander e Malmgren ${ }^{16}$ tem como principal vantagem o fato de esta padronização das radiografias iniciais não ser necessária, estando assim passíveis de comparação nas diversas fases do tratamento. Além disso, devido à eliminação do erro do método intra-examinador, o resultado adquire maior confiabilidade.

A avaliação estatística adotada identificou uma diferença ao nível de 0,0466 entre as médias dos escores dos dois grupos, representando um menor índice de reabsorção radicular no grupo 2 , que utilizou braquetes totalmente programados e apenas fios de níquel-titânio. Entretanto, quando se sobrepõem os intervalos de confiança com os limites máximo e mínimo, citados na tabela 2 , verifica-se uma margem de coincidência, quer dizer, clinicamente os pacientes podem ter as mesmas quantidades de reabsorção radicular em resposta aos dois tipos de tratamento propostos, mesmo identificando-se uma diferença estatisticamente significante.
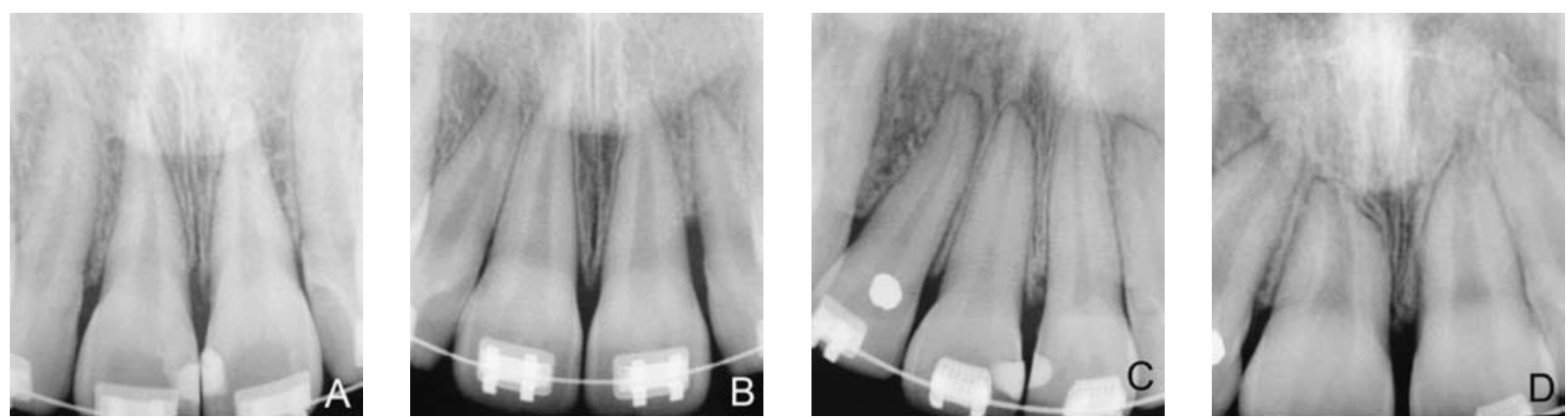

FIGURA 5 - Radiografias digitais tomadas durante ou na fase final do tratamento ortodôntico de pacientes selecionados aleatoriamente da amostra total, nas quais encontramos exemplos de escores 0 (A), 1 (B), 2 (C) e 3 (D). 
Ressalta-se que a mediana, que representa 50\% dos pacientes, no grupo 1 apresentou o escore 2 e no grupo 2 o escore 1, predominantemente. Também no grupo 2 nota-se que dois pacientes apresentaram escore 0 , ou seja, o mínimo de reabsorção identificado e apenas um apresentou escore 3. Já no grupo 1, o mínimo de reabsorção encontrado foi o escore 1, sendo que dois pacientes apresentaram escore 3 , contrapondo com apenas um do grupo 1 com esse escore (Fig. 5).

De acordo com a metodologia adotada e os dados supracitados, inferimos que a reabsorção radicular pode ser determinada parcialmente pela mecânica ortodôntica adotada. Foram observados indícios que sugerem menores reabsorções radiculares quando se utiliza braquetes pré-programados associados a fios de níquel-titânio.

Apesar da preocupação em se estabelecer um único profissional para a realização do tratamento ortodôntico, os recursos disponíveis não permitem aferições sobre as forças aplicadas sobre um dente quanto à sua magnitude e vetorização. Esta padronização ainda é dificultada, já que a aplicação dos acessórios ortodônticos, como a colagem de braquetes, nem sempre é uniforme e perfeita em todos os dentes e todos os pacientes ${ }^{8}$. Como uma justificativa para a ocorrência de diferentes graus de reabsorção dentária, estariam estes aspectos vinculados à técnica.

Como a reabsorção radicular apical externa ocorreu, em maior ou menor grau, independentemente da mecanoterapia empregada, enfatiza-se a importância da obtenção de radiografias periapicais no início e seis meses depois de iniciado o tratamento, com o objetivo de avaliar o comportamento radicular antes e durante o tratamento ortodôntico ${ }^{6,7,15,16}$. A utilização de radiografias periapicais de boa qualidade no planejamento ortodôntico se fundamenta ainda como conduta preventiva de problemas profissionais e biológicos, quanto à ocorrência de reabsorções prévias ao tratamento ${ }^{8}$.

Janson et al. ${ }^{13}$ lançaram mão de radiografias periapicais para compararem o nível de reabsorção radicular apical em incisivos centrais superiores e inferiores após o tratamento ortodôntico com três diferentes técnicas e aparelhos. A amostra utilizada foi dividida em três grupos de 30 pacientes, de acordo com o tratamento realizado: grupo 1) tratado com a técnica Edgewise padrão, grupo 2) Edgewise pré-programado e grupo 3) tratado com terapia bioeficiente. A análise realizada por dois examinadores por meio do sistema de escores proposto por Levander e Malmgren ${ }^{16}$ mostrou que o grupo 3 foi o que apresentou menores níveis de reabsorção. Especulou-se que a menor reabsorção foi devida ao uso de fios modernos super-elásticos e termo-ativados. A maior parte da amostra total $(53,37 \%)$ apresentou um grau moderado de reabsorção radicular.

Neste estudo, a análise dos escores nos permite considerar que o tratamento realizado com a técnica Edgewise com acessórios totalmente programados e fios de níquel-titânio apresenta menor média de reabsorção radicular apical, quando comparada à técnica Edgewise com acessórios padrão e fios de aço inoxidável.

Este resultado pode ser explicado, em parte, pelo emprego de ligas de níquel-titânio, que promovem um menor estresse no dente e periodonto, devido às suas propriedades de maior deflexão e liberação de forças mais suaves $^{11,14}$. Devemos considerar, entretanto, que não existe uma liga melhor para qualquer situação. A opção pelo fio mais adequado requer uma avaliação clínica e diagnóstico adequados, bem como planejamento correto do tratamento ortodôntico. Para as técnicas que dependem do deslizamento durante a retração de caninos, por exemplo, o baixo atrito é fundamental para a eficiência da mecânica e os fios de aço inoxidável são recomendáveis ${ }^{11}$.

Um outro fator a ser ponderado, considerando a relação entre a técnica ortodôntica e a reabsorção radicular, é a utilização de um tipo de aparelho 
que reduza o tempo de tratamento. Uma vez que as posições individuais dos dentes já estão incutidas nos braquetes, na técnica que utilizou acessórios totalmente programados (Grupo 2), o que ocorre é uma diminuição do número de ajustes individuais pelo profissional. A relação entre tempo de tratamento com aparelhagem fixa e reabsorção radicular já foi descrita por Brin et al. ${ }^{5}$ Os autores, estudando 138 crianças com má oclusão de Classe II tratadas por meio de três abordagens terapêuticas seguidas de aparelhagem fixa, encontraram associações significativas entre maior tempo de tratamento e maiores graus de reabsorção radicular apical externa.

\section{CONCLUSÕES}

1) O tratamento ortodôntico como um todo apresentou moderado grau de reabsorção radicular apical, qualquer que tenha sido a mecanoterapia empregada.

2) O tratamento ortodôntico empregando a técnica Edgewise com acessórios totalmente programados e fios de níquel-titânio foi o que apresentou menores graus de reabsorção radicular apical, em comparação à técnica Edgewise com acessórios padrão e fios de aço inoxidável.

\title{
Computer-assisted radiographic evaluation of apical root resorption following orthodontic treatment with two different fixed appliance techniques
}

\begin{abstract}
Aim: external apical root resorption is frequently observed during and after orthodontic treatment and can be related to factors such as mechanical factors, magnitude of forces and treatment time with fixed appliances. This study investigated by means of computerized radiographs the amount of root resorption after orthodontic treatment with two different fixed appliance techniques: standard Edgewise technique and Straight-wire system. Methods: the sample was comprised of 20 patients treated by the same orthodontist at the Orthodontic Clinic of Araçatuba Dental School, University of São Paulo State - UNESP. The patients were divided into two groups: group 1 (treated with standard Edgewise technique and stainless steel wires) and group 2 (treated with Straight-wire system and nickel-titanium alloys). The computerized evaluation was performed by only one examiner using Levander and Malmgren's score system (1988) in the radiographs obtained at the beginning of the orthodontic treatment, after canine retraction and at the end of treatment. Results and Conclusions: external apical root resorption in patients treated with Straight-wire system and nickel-titanium alloy was lesser than in patients treated by standard Edgewise technique and stainless steel wires. However, all patients presented moderate external apical root resorption regardless of the fixed appliance technique.
\end{abstract}

Key words: Corrective Orthodontics. Root resorption. Computer-assisted image interpretation.

\section{REFERÊNCIAS}

1. BECK, B. W.; HARRIS, E. F. Apical root resorption in orthodontically treated subjects: analysis of Edgewise and light wire mechanics. Am J Orthod Dentofacial Orthop, St. Louis, v. 105 no. 4, p. 350-361, Apr. 1994.

2. BORG, E.; GRONDAHL, H. G. Endodontics measurements in digital radiographs acquired by a photostimulable, storage phosphor system. Endod Dent Traumatol, Copenhagen, v. 12 no. 1, p. 20-24, Feb. 1996.
3. BRANDT, C.; FENYO-PEREIRA, M.; COSTA, C.; VAROLI, O. J. A influência do ensino da técnica radiográfica periapical do paralelismo preliminarmente ao da técnica radiográfica periapical da bissetriz. Rev Odont Univ São Paulo, São Paulo, v. 11, n. 2, p. 131-137, abr./jun. 1997

4. BREZNIAK, N.; WASSERSTEIN, A. Root resorption after orthodontic treatment: Part 1. Literature review. Am J Orthod Dentofacial Orthop, St. Louis, v. 103, no. 1, p. 62-66, Feb. 1993.

5. BRIN, I.; TULLOCH, J. F.; KOROLUK, L.; PHILIPS, C. External apical root resorption in Class II malocclusion: a retrospective review of 1-versus 2-phase treatment. Am J Orthod Dentofacial Orthop, St. Louis, v. 124, no. 2, p. 151-156, Aug. 2003. 
6. CAPELOZZA FILHO, L.; BENICÁ, N. C. M.: SILVA FILHO, O. G. CAVASSAN, A. O. Reabsorção radicular na clínica ortodôntica: aplicação de um método radiográfico para diagnóstico precoce. Ortodontia, São Paulo, v. 35, n. 2, p. 14-26, abr./jun. 2002

7. CAPELOZZA FILHO, L.; SILVA FILHO, O. G. Reabsorção radicular na clínica ortodôntica: atitudes para uma conduta preventiva. R Dental Press Ortodon Ortop Facial, Maringá, v. 3, n. 1 p. 104-126, jan./fev. 1998.

8. CONSOLARO, A. Reabsorções dentárias nas especialidades clínicas. Maringá: Dental Press, 2002.

9. DERMAUT, L. R.; DE MUNCK, A. Apical root resorption of upper incisors caused by intrusive tooth movement: a radiographic study. Am J Orthod Dentofacial Orthop, St. Louis, v. 90, no. 4, p. 321-326, Oct. 1986.

10. DIGORA Instruction Manual. Finland: Soredex, 1994. p. 1-5.

11. GURGEL, J. A.; RAMOS, A. L.; KERR, S. D. Fios ortodônticos. R Dental Press Ortodon Ortop Facial, Maringá, v. 6, n. 4, p. 103-114, jul./ago. 2001.

12. HENDRIX, I.; CARELS, C.; KUJIPERS-JAGTMAN, A. M.; VAN'T HOF, M. A radiographic study of posterior apical root resorption in orthodontic patients. Am J Orthod Dentofacial Orthop, St. Louis, v. 105, no. 4, p. 345-349, Apr. 1994.

13. JANSON, G. R.; DE LUCA CANTO, G.; MARTINS, D. R.; HEN RIQUES, J. F. DE FREITAS, M. R. A radiographic comparison of apical root resorption after orthodontic treatment with 3 different fixed appliance techniques. Am J Orthod Dentofacial Orthop, St. Louis, v. 118, no. 3, p. 262-273, Sept. 2000.

14. KUSY, R. P. A review of contemporary archwires: their properties and characteristics. Angle Orthod, Appleton, v. 67, no. 3, p. 197-208, June 1997.

15. LEVANDER, E.; BAJKA, R.; MALMGREN, O. Early radiographic diagnosis of apical root resorption during orthodontic treatment: a study of maxillary incisors. Eur J Orthod, London, v. 20, no. 1, p. 57-63, Feb. 1998

16. LEVANDER, E.; MALMGREN, O. Evaluation of the risk of root resorption during orthodontic treatment: a study of upper incisors. Eur J Orthod, London, v. 10, no. 1, p. 30-38, Feb. 1988

17. LIM, K. F.; LOH, E. M.; HONG, Y. H. Intra oral computed radiography-an in vitro evaluation. J Dent, Bristol, v. 24, no. 5, p. 359-364, Sept. 1996

18. LUPI, J. E.; HANDELMAN, C. S.; SADOWSKY, C. Prevalence and severity of apical root resorption and alveolar bone loss in orthodontically treated adults. Am J Orthod Dentofacial Orthop, St. Louis, v. 109, no. 1, p. 28-37, Jan. 1996.

19. MARTINS, D. R.; CANSANÇÃOO, J. M.; SANCHEZ, J. F. Avaliação radiográfica da reabsorção radicular consecutiva ao tratamento ortodôntico. Ortodontia, São Paulo, v. 27, n. 3, p. 4-8, jan./abr. 1994.

20. MCNAB, S.; BATTISTUTTA, D.; TAVERNE, A.; SYMONS, A. L. External apical root resorption following orthodontic treatment. Angle Orthod, Appleton, v. 70, no. 3, p. 227-232, June 2000.

21. MIRABELLA, A. D.; ARTUN, J. Prevalence and severity of apical root resorption of maxillary anterior teeth in adult orthodontic patients. Eur J Orthod, London, v. 17, no. 2, p. 93-99, Apr. 1995.

22. MIRABELLA, A. D.; ARTUN, J. Risk factors for apical root resorption of maxillary anterior teeth in adult orthodontic patients. Am J Orthod Dentofacial Orthop, St. Louis, v. 108, no. 1, p. 48-55, July 1995.

23. ODENRICK, L.; BRATTSTROM, V. Nailbitinhg: frequency and association with root resorption during orthodontics treatment. Br J Orthod, London, v. 12, no. 2, p. 78-81, Apr. 1985.

24. REMINGTON, D. N.; JOONDEPH, D. R.; ARTUN, J.; RIEDEL, R. A.; CHAPKO, M. K. Long-term evaluation of root resorption occurring during orthodontic treatment. Am J Orthod Dentofacial Orthop, St. Louis, v. 96, no. 1, p. 43-46, July 1989.

25. REUKERS, E.; SANDERINK, G.; KUJIPERS-JAGTMAN, A. M. VAN'T HOF, M. Assessment of apical root resorption using digital reconstruction. Dentomaxillofac Radiol, Tokyo, v. 27, no. 1 p. 25-29, Jan. 1998

26. SILVA FILHO, O. G.; BERRETA, E. C.; CAVASSAN, A. O.; CAPELOZZA FILHO, L. Estimativa da reabsorção radicular em 50 casos ortodônticos bem finalizados. Ortodontia, São Paulo, v. 26, n. 1, p. 24-37, jan./abr. 1993.

27. SILVA FILHO, O. G.; LARA, T. S.; ALMEIDA, A. M.; SILVA, H. C.: SÁNCHEZ, J. F. Identificación anatómica de estructuras del maxilar mediante 2 métodos de diagnóstico. Radiografía y tomografía computarizada. Estudio comparativo. Rev Esp Ortod Madrid, v. 35, p. 55-68, 2005.

28. SILVA FILHO, O. G.; MENDES, O. F.; OZAWA, T. O.; FERRARI Jr, F. M.; CORREA, T. M. Behavior of partially formed roots of teeth submitted to orthodontic movement. J Clin Pediatric Dent, Birmingham, v. 28, no. 2, p. 147-154, Winter 2004.

29. SPURRIER, S. W.; HALL, S. H.; JOONDEPH, D. R.; SHAPIRO, P. A.; RIEDEL, R. A. A comparison of apical root resorption during orthodontic treatment in endodontically treated and vita teeth. Am J Orthod Dentofacial Orthop, St. Louis, v. 97, no. 2, p. 130-134, Feb. 1990.

30. WENZEL, A.; GRONDAHL, H. G. Direct digital radiography in the dental office. Int Dent J, London, v. 45, no. 1, p. 27-34, Feb. 1995.
Endereço de correspondência

Eduardo César Almada Santos

Rua José Bonifácio, 1193 - Vila Mendonça

CEP: 16.015-050 - Araçatuba/SP

E-mail: almada@foa.unesp.br 